\title{
KIS, a Kinase Associated with Microtubule Regulators, Enhances Translation of AMPA Receptors and Stimulates Dendritic Spine Remodeling
}

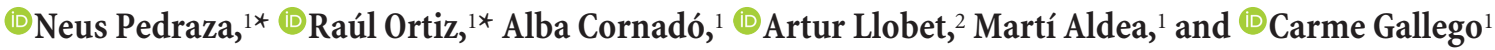 \\ ${ }^{1}$ Molecular Biology Institute of Barcelona (IBMB-CSIC), 08028 Barcelona, Catalonia, Spain and ${ }^{2}$ Laboratory of Neurobiology, Bellvitge Biomedical Research \\ Institute (IDIBELL) and University of Barcelona, 08907 L'Hospitalet de Llobregat, Spain
}

Local regulation of protein synthesis allows a neuron to rapidly alter the proteome in response to synaptic signals, an essential mechanism in synaptic plasticity that is altered in many neurological diseases. Synthesis of many synaptic proteins is under local control and much of this regulation occurs through structures termed RNA granules. KIS is a protein kinase that associates with stathmin, a modulator of the tubulin cytoskeleton. Furthermore, KIS is found in RNA granules and stimulates translation driven by the $\beta$-actin $3^{\prime}$ UTR in neurites. Here we explore the physiological and molecular mechanisms underlying the action of KIS on hippocampal synaptic plasticity in mice. KIS downregulation compromises spine development, alters actin dynamics, and reduces postsynaptic responsiveness. The absence of KIS results in a significant decrease of protein levels of PSD-95, a postsynaptic scaffolding protein, and the AMPAR subunits GluR1 and GluR2 in a CPEB3-dependent manner. Underlying its role in spine maturation, KIS is able to suppress the spine developmental defects caused by CPEB3 overexpression. Moreover, either by direct or indirect mechanisms, KIS counteracts the inhibitory activity of CPEB3 on the GluR2 3'UTR at both mRNA translation and polyadenylation levels. Our study provides insights into the mechanisms that mediate dendritic spine morphogenesis and functional synaptic maturation, and suggests KIS as a link regulating spine cytoskeleton and postsynaptic activity in memory formation.

Key words: AMPA receptors; hippocampus; KIS; local translation; spine remodeling; synaptic plasticity

\section{Introduction}

In the mammalian forebrain, most glutamatergic excitatory synapses occur on postsynaptic spines. Dendritic spines are highly plastic and can rapidly change morphology in response to numerous stimuli. This dynamic remodeling of dendritic spines is thought to be critical for information processing, memory, and cognition. In postsynaptic forms of plasticity, activity-induced morphological remodeling and enhanced synaptic transmission can be specific to a single dendritic spine and requires both protein synthesis and increased polymerization of the cytoskeletal protein $\beta$-actin (Caroni et al., 2012; Penzes and Rafalovich, 2012).

\footnotetext{
Received April 17, 2014; revised Aug. 8, 2014; accepted Aug. 13, 2014.

Author contributions: N.P., R.O., M.A., and C.G. designed research; N.P., R.O., A.C., A.L., and C.G. performed research; N.P., R.O., M.A., and C.G. analyzed data; C.G. wrote the paper.

This work was supported by the Ministry of Economy and Competitiveness of Spain (BFU2011-25914), Consolider-Ingenio 2010 (CSD2007-15), and the European Union (FEDER). We thank Elena Rebollo for excellent assistance in confocal microscopy. We thank Francisco López for help with electrophysiological experiments and Elisa Izaurralde and Raúl Mendez for generously providing plasmids and proteins. We are grateful to Marta Rafel for help in some experiments. We thank Erin Schuman and Raúl Mendez for helpful comments. We thank members of Aldea and Gallego laboratories for stimulating discussions and ideas.

*N.P. and R.O. contributed equally to this work.

The authors declare no competing financial interests.

Correspondence should be addressed to Carme Gallego, Molecular Biology Institute of Barcelona (IBMB-CSIC), 08028 Barcelona, Catalonia, Spain. E-mail: cggbmc@ibmb.csic.es.

DOI:10.1523/JNEUROSCI.1573-14.2014

Copyright $\odot 2014$ the authors $\quad 0270-6474 / 14 / 3413988-10 \$ 15.00 / 0$
}

Accumulating evidence suggests that synthesis of many plasticityrelated proteins is subject to multilayered post-transcriptional control with concerted actions of multiple RNA-binding proteins (RBPs). Regulation of the localization, stability, and translation of mRNAs is mediated in part by RBPs that bind to mRNAs in untranslated ( $5^{\prime}$ and/or $3^{\prime}$-UTR) or coding regions. RBPs regulate mRNA distribution and metabolism by consolidating RNAprotein complexes to form RNA granules in which translation is repressed (Darnell and Richter, 2012; Tolino et al., 2012; Holt and Schuman, 2013).

KIS was first identified as a kinase that interacts with stathmin (Maucuer et al., 1997), a phosphoprotein that controls microtubule dynamics with a role in axon development (Watabe-Uchida et al., 2006). KIS is the only known protein kinase that possesses a U2AF homology motif (UHM), which mediates protein-protein interactions at the C-terminal region of KIS. This motif shares $42 \%$ sequence similarity with U2AF65, a $65 \mathrm{kDa}$ subunit of the splicing factor U2AF, suggesting that KIS could be involved in RNA-related processes (Kielkopf et al., 2004). Although KIS is ubiquitously expressed, higher levels are detected in the nervous system (Bièche et al., 2003), and KIS mRNA level increases gradually during postnatal development, reaching its highest level in the mature brain. We have previously shown that KIS interacts with KIF3A, NonO, and eEF1A, three proteins found in RNA granules; colocalizes with KIF3A kinesin in neurites; and is required for proper neurite outgrowth in cortical mouse neurons. 
In addition, we showed that KIS stimulates translation driven by the $\beta$-actin $3^{\prime}$ UTR, suggesting that KIS could be a modulator of mRNA translation in dendrites (Cambray et al., 2009). Behavioral studies with KIS knock-out mice have shown that KIS is important for normal spontaneous activity and fear conditioning of adult animals. KIS-deficient mice present reduced learning capacities from aversive stimuli suggesting a role for KIS in brain programming during development (Manceau et al., 2012). Interestingly, stathmin knock-out mice failed to induce LTP in afferent inputs to the amygdale, pointing to stathmin as a key factor in regulating both innate and learned fear (Shumyatsky et al., 2005). To seek the functional significance of KIS in synaptic plasticity, we examined the molecular alterations and physiological consequences of KIS loss in hippocampal neurons. We observed that KIS knockdown reduced expression levels of PSD-95 and AMPAR proteins, partly by modulating CPEB3 activity, producing morphological and functional modifications at excitatory synapses.

\section{Materials and Methods}

Hippocampal neuron culture. Hippocampi were dissected from E17.5 CD1 mice (undetermined sex) in HBSS containing $0.6 \%$ glucose and 10 mM HEPES. After dissection, tissues were trypsinized (Life Technologies) in $\mathrm{HBSS}$ at $37^{\circ} \mathrm{C}$ for $15 \mathrm{~min}$. Enzymatic digestion was stopped by washing the tissue three times with MEM (Life Technologies) supplemented with $10 \%$ FBS and $0.8 \%$ glucose. Hippocampi were left to sediment between washes, and centrifugation was avoided to keep cell viability. Trypsintreated tissue was then mechanically disaggregated by passing through a flame-polished Pasteur pipette ( $\sim 10$ times). Cells were plated at desired density on Poly-L-lysine (Sigma)-coated plates $(0.5 \mathrm{mg} / \mathrm{ml}$ Poly-L-lysine in borate buffer, $\mathrm{pH}$ 8.5) and maintained in MEM, 10\% FBS, $0.8 \%$ glucose, and 1\% GlutaMAX (Life Technologies) for 2-4 h. Culture medium was then substituted for Neurobasal (Life Technologies) supplemented with 2\% B27 (Life Technologies) and 1\% GlutaMAX.

Primary hippocampal cultures were transfected using the CalPhos mammalian transfection kit (Clontech) as previously described (Jiang and Chen, 2006) or Lipofectamine LTX and PLUS reagent (Life Technologies) following the manufacturer's instructions.

Lentivirus production and infection. The shRNA sequences in PLKO.1puro lentiviral vector (Sigma) were as follows: GCAAATCGTACTTCCCTCCTAA (TRCN0000190074) targeted against mouse CPEB3, GAGTGCGGAGAATGAGTGTTT (TRCN0000027622) against mouse KIS, and the control non-mammalian shRNA (shc002). 293FT cells were transfected with Lipofectamine 2000 (Life Technologies) with lentiviral vector, envelope plasmid pVSV-G, and packaging plasmid pHR' $82 \Delta R$, and cultured in DMEM 10\% FBS. Lentiviruses were harvested 2 and $3 \mathrm{~d}$ after transfection, filtered through $0.45 \mu \mathrm{m}$ cellulose-acetate syringe filters, and concentrated by centrifugation at $26,000 \mathrm{rpm}$ for $2 \mathrm{~h}$ at $4^{\circ} \mathrm{C}$. For knockdown experiments, hippocampal neurons cultured for 3-4 DIVs were infected with lentiviruses overnight, and collected as indicated.

Spine analysis using SpineJ software. SpineJ has been designed to obtain quantitative information of dendritic spines from fluorescence confocal images. As a prerequisite, neurons must express a fluorescent protein to levels high enough to clearly highlight neurites and spines above a darker background. Specific procedures using object libraries supplied in ImageJ (Wayne Rasband, NIH) were written to detect cell boundaries along neurites as pixels markedly brighter compared with background. The user first defines the neurites (tracks) to be analyzed with a softwareassisted tool and, then, a recurrent algorithm detects individual protrusions along each track to obtain a number of spine dimensions (height, width, area) and, if multichannel stacks are provided, the corresponding fluorescence density values for each channel. SpineJ software will be available upon request. Images were acquired using a Zeiss LSM780 confocal microscope. Stacks of $\sim 10$ slices were imaged every $0.37 \mu \mathrm{m}$ (maximal $z$ resolution in our conditions), with a pinhole value of 1 Airy unit. For correct visualization of spine morphology, a $63 \times$ objective at 0.11 $\mu \mathrm{m} /$ pixel was used. Laser power and PMT values were optimized depending on fluorescent signals.

Electrophysiology. Whole-cell recording of miniEPSCs was performed in hippocampal neuron cultures at 17-21 DIV. Typical resistances of pipettes used for recordings were 3-4 $\mathrm{M} \Omega$ when filled with internal solution, with the following composition: $130 \mathrm{~mm} \mathrm{~K}$-gluconate, $4 \mathrm{~mm}$ $\mathrm{MgCl}_{2}, 1 \mathrm{~mm}$ EGTA, $10 \mathrm{~mm}$ HEPES, $3 \mathrm{~mm} \mathrm{Na} \mathrm{ATP}_{2}$, and $1 \mathrm{~mm} \mathrm{NaGTP}$, $\mathrm{pH} 7.2,290 \mathrm{mOsm} / \mathrm{kg}$. External solution contained the following: 130 $\mathrm{mm} \mathrm{NaCl}, 5 \mathrm{~mm} \mathrm{KCl}, 2 \mathrm{~mm} \mathrm{MgCl}$, 10 mM HEPES-hemisodium salt, 10 mm glucose, $1 \mu \mathrm{M}$ TTX, and $10 \mu \mathrm{m}$ picrotoxin, $\mathrm{pH}$ 7.4. The final $2 \mathrm{~mm}$ $\mathrm{CaCl}_{2}$ concentration was always achieved by dilution from a $1 \mathrm{~m}$ stock solution (Sigma-Aldrich). Salts were from Sigma-Aldrich. Before the addition of glucose and $\mathrm{CaCl}_{2}$, the osmolarity of the external solution was adjusted to $290 \mathrm{mOsm} / \mathrm{kg}$. All experiments were performed at room temperature $\left(23^{\circ} \mathrm{C}\right)$.

Immunofluorescence. Hippocampal neurons were fixed using preheated $4 \%$ PFA and $4 \%$ sucrose in PBS for 30 min at room temperature and then washed three times with PBS. Neurons were permeabilized for 5 min with $0.1 \%$ Triton X-100 and blocked with 5\% NGS in PBS (blocking solution). Primary antibodies $\alpha$-GluR1 (Millipore catalog \#AB1504, RRID:AB_2113602), $\alpha$-GluR2 (Sigma-Aldrich catalog \#SAB4300535, RRID:AB_10621300), or $\alpha$-PSD-95 (EMD Millipore catalog \#MABN68, RRID:AB_10807979) were used diluted 1:400 in blocking solution. Proteins were detected by incubation with secondary antibodies Alexa 568 donkey anti-rabbit (Life Technologies catalog \#A10042, RRID:AB_11180183) or Alexa 568 donkey anti-mouse (Life Technologies catalog \#A10037, RRID:AB_11180865) diluted 1:2000 in blocking solution. Images were acquired with a Zeiss LSM780 confocal microscope using the following parameters: $\sim 15-\mu \mathrm{m}$-thick stacks were imaged every $0.5 \mu \mathrm{m}$ (pinhole set at 1 Airy unit), under a $63 \times$ objective $(0.13 \mu \mathrm{m} /$ pixel $)$. Laser power and PMT values were kept constant throughout images and conditions. Immunofluorescence quantification was performed using Image (Wayne Rasband, NIH). For detection of filamentous actin, phalloidin-rhodamine (Sigma, P1951) was used at 2 $\mathrm{U} / \mathrm{ml}$ in blocking solution following the same protocol as for immunofluorescence. Images were acquired with the same settings used to analyze synaptic spines, and fluorescence quantification was performed with the SpineJ plugin as described above.

Immunoprecipitations and Western blot analysis. Immunoprecipitation and immunoblotting protocols have been described previously (Cambray et al., 2009). Antibodies used for immunoblotting were as follows: $\alpha$-KIS (1:100; made in collaboration with AbBCN), $\alpha$-CPEB3 (1:500; Abcam catalog \#ab10883, RRID:AB_442831), $\alpha$-GluR1 (1:500; Millipore catalog \#AB1504, RRID:AB_2113602), $\alpha$-GluR2 (1:500; SigmaAldrich catalog \#SAB4300535, RRID:AB_10621300), $\alpha$-PSD95 (1: 2000; EMD Millipore catalog \#MABN68, RRID:AB_10807979), $\alpha$-tubulin (1:2000; Sigma-Aldrich catalog \#T5168, RRID:AB 477579), $\alpha$-FLAG M2 (1:2000; Sigma-Aldrich catalog \#F3165, RRID: AB_259529), $\alpha$-VDAC (1:1000; Abcam catalog \#ab15895, RRID: AB_2214787), IRDye 680RD (1:10,000; LI-COR Biosciences catalog \#926-68070, RRID:AB_10956588), and IRDye 800CW (1:10,000; LI-COR Biosciences catalog \#926-32210, RRID:AB_621842).

BONCAT analysis. Bio-orthogonal noncanonical amino acid tagging (BONCAT) protocol described in Dieterich et al. (2007) was followed using copper sulfate and tris(2-carboxyethyl)phosphine (TCEP) instead of copper bromide to generate the $\mathrm{Cu}(\mathrm{I})$ catalyst for the copper-catalyzed azide-alkyne cycloaddition (CuAAC) reaction. Briefly, hippocampal cells were depleted of methionine for $30 \mathrm{~min}$ before labeling with $1 \mathrm{~mm}$ noncanonical amino acid AHA (azidohomoalanine; Jena Bioscience) for $4 \mathrm{~h}$. After harvesting and lysis in PBS, pH 7.6, with 0.05\% SDS and protease and phosphatase inhibitors, the CuAAC reaction was set up as follows: $200 \mu \mathrm{M}$ triazole ligand, $50 \mu \mathrm{M}$ biotin-alkyne, $400 \mu \mathrm{M}$ TCEP, and $200 \mu \mathrm{M}$ copper sulfate, and incubated at $4^{\circ} \mathrm{C}$ overnight under agitation. The CuAAC reaction was centrifuged at $2000 \times g$ at $4^{\circ} \mathrm{C}$ for $5 \mathrm{~min}$ and excess reagents were removed by gel filtration using PD-10 columns (GE Healthcare) and eluted in $0.05 \%$ SDS in PBS, pH 7.6. A dot-blot analysis was performed to determine the newly synthesized protein concentration for the NeutrAvidin purification. Desalted samples were precipitated with NeutrAvidin resin (Pierce/Thermo) overnight at $4^{\circ} \mathrm{C}$. After 
the binding reaction was complete, NeutrAvidin beads were washed three times with $1 \% \mathrm{NP}-40$ in PBS, pH 7.6, and eluted with SDS sample buffer. AHA-labeled samples were developed with IRDye 800CW streptavidin (1:1000; LI-COR Biosciences, PN926-32230).

Surface biotinylation. For surface biotinylation (all steps performed on ice) hippocampal cells were washed twice with PBS-MC (1 mM $\mathrm{MgCl}_{2}$ and $0.1 \mathrm{mM} \mathrm{CaCl}_{2}$ ) and incubated with $1 \mathrm{mg} / \mathrm{ml}$ sulfo-NHS-SS-biotin (Pierce), a nonpermeable biotin, in PBS-MC for $15 \mathrm{~min}$. Following surface labeling, nonconjugated biotin was quenched by washing twice with TBS. Cells were lysed in RIPA buffer containing the following: $50 \mathrm{~mm}$ Tris, pH7.4, $150 \mathrm{~mm} \mathrm{NaCl}, 1 \% \mathrm{NP}-40,0.1 \%$ SDS, 5 mm EDTA, phosphatase inhibitors and $1 \times$ EDTA-free protease inhibitors cocktail (Roche), and protein concentrations were determined using a DC protein assay (Bio-Rad). Equal amounts of protein (usually $1 \mathrm{mg}$ in $500 \mu \mathrm{l}$ ) were incubated overnight with $20 \mu \mathrm{l}$ NeutrAvidin-coated beads (Pierce) at $4^{\circ} \mathrm{C}$ with constant rotation. The next day, beads were washed three times with RIPA buffer and eluted samples were processed for immunoblotting.

Luciferase assay. Luciferase assays were performed using the Gaussia and Cypridina Luciferase assay Flash Kits (Thermo Scientific), essentially following the manufacturer's instructions. Plasmids pCMV-Gaussia luciferase and pCMV-Cypridina luciferase were kind gifts from Raúl Mendez. Routinely, $100 \mathrm{ng}$ of Gaussia luciferase reporter plasmid (pCMV-Gaussia luciferase-3'UTR GluR2) and 50 ng of pCMVCypridina luciferase control plasmid were transfected in HEK293T cells (24-well culture plates) to determine relative expression values. To assess effects caused by CPEB3 and KIS, $0.1 \mu \mathrm{g}$ or $0.9 \mu \mathrm{g}$ of each expression plasmid (or empty vector) was added to each transfection assay. Twentyfour hours post-transfection culture medium was replaced with fresh medium, and $2 \mathrm{~h}$ later $20 \mu \mathrm{l}$ of medium was collected for measuring secreted luciferase activity. The Gaussia/Cypridina luciferase ratio was obtained to correct for transfection efficiency differences among samples, and the resulting values were normalized to control conditions. The 3'UTR of GluR2 was cloned in pCMV-Gaussia luciferase vector using the following primers: forward $5^{\prime}$ - $\operatorname{cgcg}$ TCTAGAcagagctcagttttaggcag- $3^{\prime}$ and reverse 5' -gcgcgGAATTCttctcattattagattgatatacc-3' (Pavlopoulos et al., 2011).

RNA immunoprecipitation and quantitative PCR. The 3'UTR of GluR2 was cloned in pGL3b vector using the following primers: forward $5^{\prime}$ cgcgTCTAGAcagagctcagttttaggcag- $3^{\prime}$ and reverse $5^{\prime}$-cgcgGTCGAC ttctcattattagattgatatacc-3' (Pavlopoulos et al., 2011). HEK293T cells were transfected with the Firefly luciferase ORF fused to the $3^{\prime}$ UTR of GluR2 (pGL3b-3'UTR GluR2) in combination with plasmid vectors expressing FLAG, FLAG-CPEB3, or FLAG-CPEB3 plus KIS. The immunoprecipitation protocol was adapted from Chao et al. (2013). Briefly, $24 \mathrm{~h}$ post-transfection cells were homogenized in RNA immunoprecipitation (RIP) buffer (DEPC-treated water containing 20 mM HEPES, pH 7.4, 150 $\mathrm{mm} \mathrm{NaCl}, 1 \mathrm{~mm} \mathrm{MgCl}{ }_{2}, 0.5 \%$ Triton X-100, 0.5\% NP-40, 10\% glycerol, $0.5 \mathrm{~mm}$ DTT, $1 \times$ protease inhibitor cocktail, and $40 \mathrm{U} / \mathrm{ml}$ RNase inhibitor). Following two rounds of centrifugation $(10 \mathrm{~min}$ at $1000 \times g$ and 10 min at $10,000 \times g$ ), cell lysates were immunoprecipitated with $\alpha$-FLAGagarose (M2; Sigma). Precipitated mRNAs were extracted (E.Z.N.A. total RNA Kit I; Omega Bio-Tek), and reverse transcribed with Superscript III reverse transcriptase (Invitrogen). Obtained cDNA levels were determined by quantitative real-time PCR using TaqMan probes for GADPH (Life Technologies catalog \#4326317E) and Firefly luciferase (forward 5'-GAAGACGCCAAAAACATA-3', reverse 5'-CGTATCTCTTCAT AGCCTTA-3', probe $5^{\prime}$-AAGATGGAACCGCTGGAGAGCAA-3'), to obtain Firefly luciferase/GAPDH ratios.

Polyadenylation assay. The Poly(A) tail-length assay kit (USBAffymetrix) was used following the manufacturer's instructions. The detection of the poly(A) tails of GluR2 mRNA was essentially performed as in Pavlopoulos et al. (2011), using a gene-specific sense oligonucleotide located upstream of the polyadenylation signal sequence and a universal primer provided by the manufacturer. PCRs using two gene-specific primers located upstream of the polyadenylation signal sequence were used to test the initial input for each tested sample (reverse transcription product) and the expected starting molecular size of the poly(A)-specific amplicons. A one-step PCR protocol was used with forward $5^{\prime}$ -
GGAAAGACCAAAATAATTATGAACT- ${ }^{\prime}$ and reverse 5' $^{\prime}$-GTTTGTTC CTTGGAGTATGACAC-3' primers (annealing at $64^{\circ} \mathrm{C}$ ). PCR products were analyzed on $2.5 \%$ agarose gels.

\section{Results}

\section{KIS is important for proper spine formation and synaptic activity}

We have shown that KIS interacts with proteins found in RNA granules, and is associated with RNP-transported mRNAs in brain extracts (Cambray et al., 2009). We hypothesized that KIS is a component of the molecular device that modulates translation in RNA-transporting granules in neurons. Loss of RNA-binding proteins in hippocampal neurons induces changes in dendritic spine morphology and synaptic transmission (Liu-Yesucevitz et al., 2011). Thus, we asked whether loss of KIS could disrupt the normal pattern of spine development. To examine the effects of KIS on mature neurons, we knocked down endogenous KIS with a lentiviral GFP-based construct that coexpressed a KIS-specific or a control shRNA. Hippocampal neurons were analyzed at 18 DIV when dendritic spines are already developed. In agreement with our published results on cortical neurons (Cambray et al., 2009), a substantial proportion of KIS knockdown neurons showed a significant decrease in dendritic complexity (Fig. $1 A, B)$. While the number of spines per micrometer was very similar (data not shown), those produced by KIS knockdown neurons showed clear signs of altered morphology, many of them having small or no spine heads (Fig. $1 A$, bottom insets). Changes in spine morphology were assessed by analyzing GFP-positive neurons with SpineJ (see Materials and Methods), which quantified area and axial dimensions of individual spines. KIS knockdown resulted in a significant decrease in the mean area of spines $\left(0.39 \pm 0.03 \mu \mathrm{m}^{2}\right)$ when compared with control neurons $(0.76 \pm$ $0.10 \mu \mathrm{m}^{2}$; Fig. $\left.1 C\right)$. To analyze this further we measured the ratio of spine length (distance from spine neck to spine tip) to spine area which, by definition, must be lower in mushroom-shaped dendritic spines than in thin filopodia-like protrusions. The spine length/area ratio in KIS knockdown neurons was $5.86 \pm$ $0.31 \mu \mathrm{m}^{-1}$ while control neurons displayed a ratio of $3.44 \pm$ $0.30 \mu \mathrm{m}^{-1}$ (Fig. 1D). These data confirmed our observation that KIS knockdown neurons produced more filopodiashaped protrusions.

Postsynaptic morphological remodeling depends on changes in polymerization of the cytoskeletal protein $\beta$-actin (Ramachandran and Frey, 2009), and we have shown that KIS stimulates neuritic translation of the $\beta$-actin mRNA (Cambray et al., 2009). Thus, we tested whether KIS also stimulates postsynaptic $\beta$-actin polymerization by phalloidin staining of hippocampal neurons at 18 DIV transfected with vectors expressing KIS and control shRNAs (Fig. $2 A, B$ ). To avoid effects due to different spine size, we only considered spines with an area of $0.5 \pm 0.25 \mu \mathrm{m}^{2}$. As shown in Figure $2 C$, a clear decrease in the mean fluorescence level of phalloidin bound to spines was observed in neurons expressing the KIS shRNA, which indicates that loss of KIS decreases polymerization of $\beta$-actin in spines.

Changes in synaptic activity drive spine morphological changes during development and synaptic plasticity, and large mushroom spines become more prominent and associated with mature synapses of high strength (Bosch and Hayashi, 2012). To determine whether knockdown of KIS also induced changes in synaptic activity, we recorded mEPSCs from hippocampal neurons 17-21 DIV infected with lentiviruses expressing KIS and control shRNAs. mEPSC amplitude is a measure of postsynaptic responsiveness, and it determines the magnitude of synaptic cur- 
A

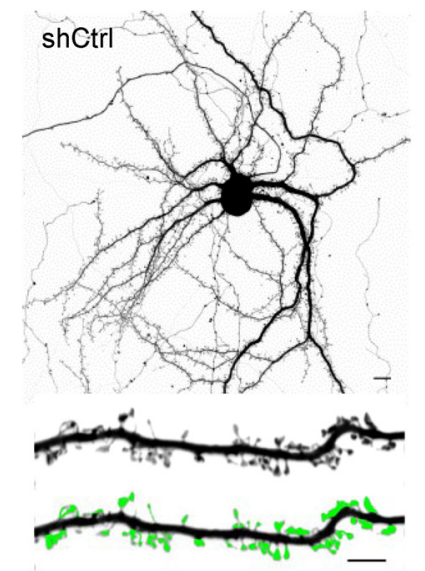

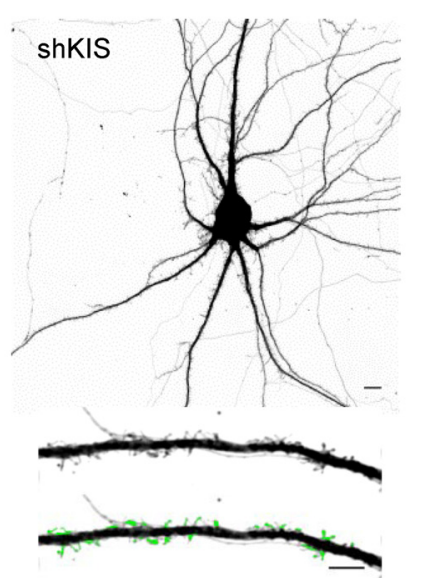

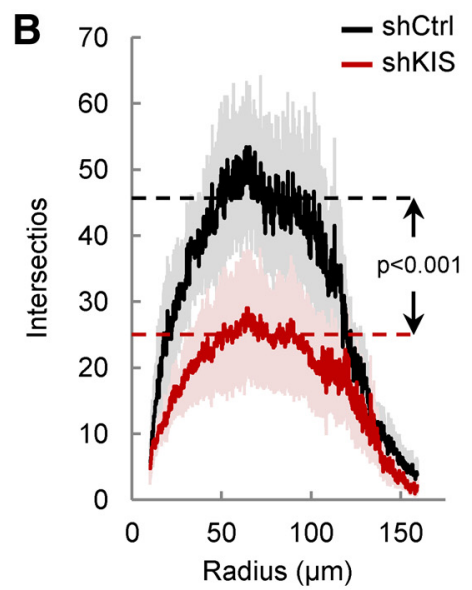

C

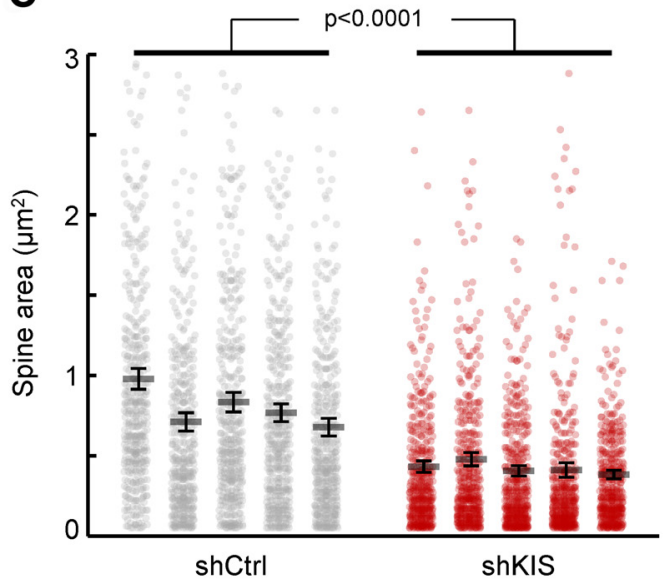

D

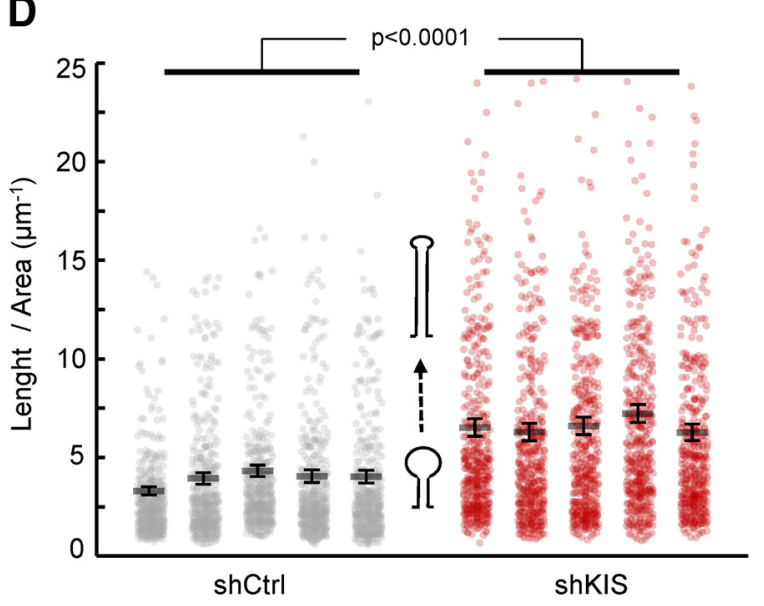

Figure 1. KIS downregulation affects spine morphology. Hippocampal neurons were transfected at 7 DIV with lentiviral vectors expressing GFP and control (shCtrl) or KIS (shKIS) shRNAs. Neurons were fixed at 18 DIV. Changes in spine number and morphology were assessed by analyzing GFP-positive neurons with SpineJ software (see Materials and Methods). $\boldsymbol{A}$, Two representative confocal images of neurons expressing shCtrl or shKIS. Scale bar, $10 \mu \mathrm{m}$. Neuritic details are shown at the bottom with protrusions detected by SpineJ labeled in green. Scale bar, $5 \mu \mathrm{m}$. $\boldsymbol{B}$, Sholl analysis of dendritic complexity in 10 neurons for each condition. Plot shows number of intersections of dendrites with concentric circles in relation to their radii. Mean values between 50 and $100 \mu \mathrm{m}$ are represented with dashed lines, and the $p$ value for a pairwise $t$ test is shown. $\boldsymbol{C}$, Area plots of dendritic spines $(n>400)$ from five shKIS-transfected neurons and five shCtrl neurons. $\boldsymbol{D}$, Length of dendritic spines $(n>400)$ relative to spine area. This ratio is lower in mushroom-shaped dendritic spines than in thin, filopodia-like protrusions. Mean values (thick horizontal lines) and confidence limits ( $\alpha=0.05$, thin vertical lines) for the mean are shown. Differences between shCtrl and shKIS-treated neurons were analyzed by ANOVA, and comparison among the indicated blocks was performed by the post hoc Scheffé's method. Obtained $p$ values are stated in each panel $(\boldsymbol{C}, \boldsymbol{D})$.

rents. In contrast, $\mathrm{mEPSC}$ frequency is used as an initial indicator of docked presynaptic vesicles and the number of functional synapses (Han and Stevens, 2009). KIS knockdown produced a 30\% decrease in the amplitude of mEPSCs (Fig. $3 A, B$ ), whereas the interevent interval only showed a minor increase (Fig. $3 C$ ). These results indicate that, consistent with previous reports (Zhang et al., 2005), morphological spine alterations affect miniature synaptic transmission and support the idea that the loss of KIS raises the number of altered synapses without significant changes in the number of spines.

\section{KIS knockdown reduces translation of PSD-95 and AMPARs in hippocampal neurons}

Postsynaptic changes in synaptic strength may be due to an altered number of postsynaptic receptors and postsynaptic density proteins (El-Husseini et al., 2000; Smith et al., 2005; Kato et al., 2007; Zheng et al., 2012). Thus, we asked whether the decrease in mEPSC amplitude induced by loss of KIS results from reduced levels of expression of AMPARs and/or the scaffolding protein PSD-95. We used hippocampal cells transfected with lentiviruses coexpressing GFP and KIS or control shRNAs as in Figure 1, and compared protein levels in GFP-positive neurons at 18 DIV with those of neighboring GFP-negative neurons by immunofluorescence and confocal microscopy. Loss of KIS decreased the expression of both AMPARs and PSD-95; the reduction is $\sim 40 \%$ compared with control neurons (Fig. $4 A, B$ ), which was significantly rescued by coexpressing KIS along with the KIS shRNA construct. The control shRNA had no significant effects on the level of these proteins (data not shown). Furthermore, hippocampal neurons expressing shRNA KIS exhibited a marked reduction of AMPARs and PSD-95 not only in the soma but also along their dendrites at 18 DIV (Fig. 4C). To confirm these observations we also measured protein levels by immunoblotting cell extracts obtained from hippocampal cells at 13-14 DIV. We found that downregulation of KIS produced a clear decrease in protein levels of PSD-95 and both GluR1 and GluR2 subunits of AMPARs in total cell extracts (Fig. 4E). All three proteins showed a similar reduction of $\sim 40 \%$ compared with control cells. Since we did not observe significant differences at the level of mRNA (data not shown), we next explored whether loss of KIS affected the de novo synthesis rate of these proteins by the BONCAT method used by Dieterich et al. 
A
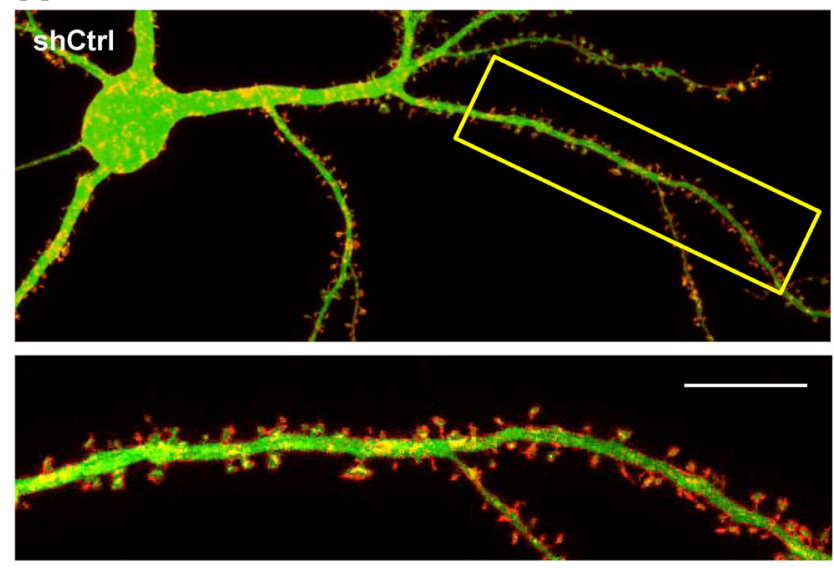

B
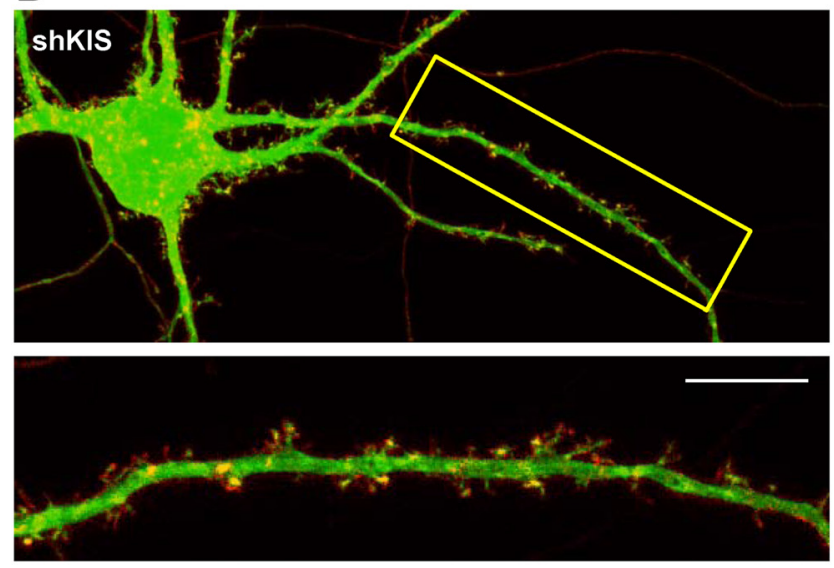

C

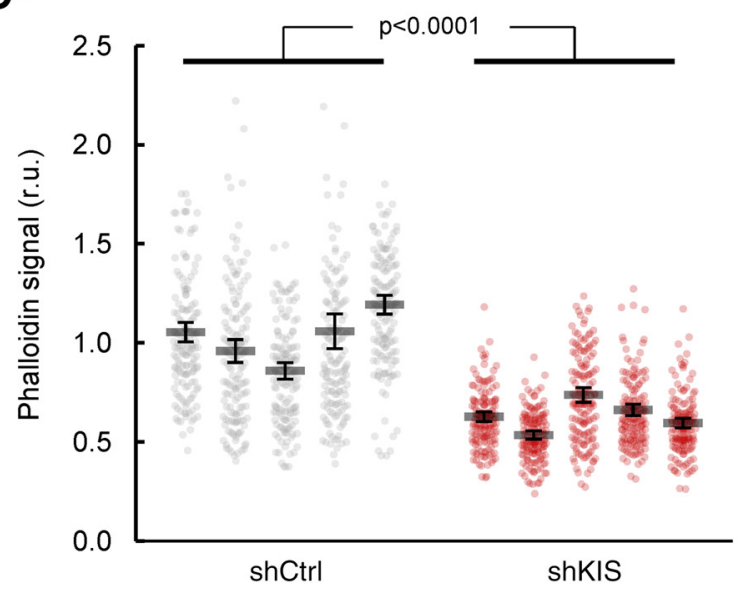

Figure 2. KIS is required for proper actin dynamics. Neuron cultures as in Figure 1 were fixed at 18 DIV and stained with phalloidin to detect $\beta$-actin polymers. Two representative confocal images of neurons expressing shCtrl $(\boldsymbol{A})$ or shKIS $(\boldsymbol{B})$. Scale bar, $20 \mu \mathrm{m}$ (GFP in green, phalloidin in red). Neuritic details are shown at the bottom. Scale bar, $10 \mu \mathrm{m}$. C, Spines from five shKIStransfected neurons and five shCtrl neurons were analyzed with SpineJ, and those with an area of $0.5 \pm 0.25 \mu \mathrm{m}^{2}$ were selected. Phalloidin levels in spines $(n=150)$ are plotted as relative values to the mean obtained from shCtrl neurons. Mean values per neuron (thick horizontal lines) and confidence limits ( $\alpha=0.05$, thin vertical lines) for the mean are shown. Differences between shCtrl and shKIS-treated neurons were analyzed by ANOVA, and comparison among the indicated blocks was performed by the post hoc Scheffés method. The obtained $p$ value is shown.
A
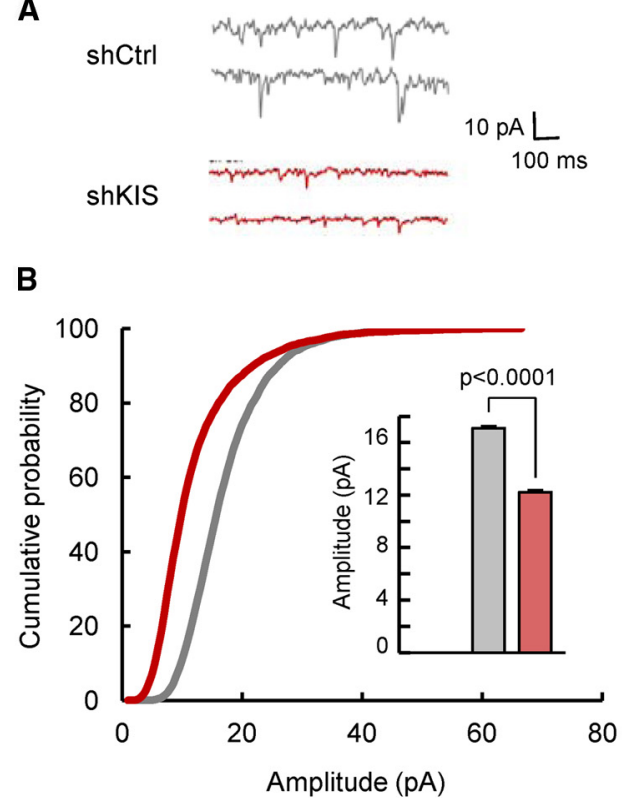

C

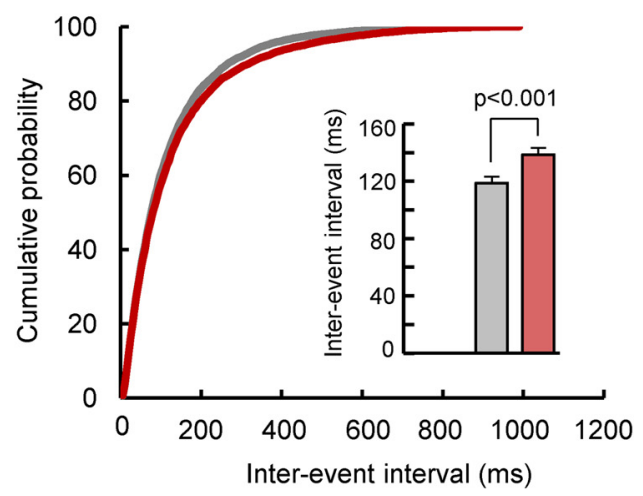

Figure 3. KIS knockdown decreases mEPSC amplitude. Hippocampal neurons were plated at low density and infected at 7 DIV with lentiviral vectors expressing GFP and control (shCtrl) or KIS (shKIS) shRNAs. Electrophysiological experiments were performed at 17-21 DIV. A, Two representative whole-cell current traces from a shCtrl neuron (gray) and a shKIS neuron (red) are shown. $\boldsymbol{B}$, Cumulative probability histograms of mini-EPSC amplitude obtained from shCtrl ( $>5700$ events from 5 neurons) and shKIS-infected neurons ( $>7300$ events from 7 neurons). Inset, Mean values and confidence limits $(\alpha=0.05)$ for the mean are plotted. $\boldsymbol{C}$, Cumulative probability histograms of mini-EPSC interevent intervals from neurons as in $\boldsymbol{B}$. Inset, Mean values and confidence limits $(\alpha=0.05)$ for the mean are plotted, and the $p$ value for a pairwise $t$ test is shown in $\boldsymbol{B}$ and $\boldsymbol{C}$.

(2007). Hippocampal cells infected with lentiviruses expressing KIS and control shRNAs were metabolically labeled with AHA, a surrogate for methionine. After conjugation to biotin, newly synthesized proteins were purified using streptavidin beads (Dieterich et al., 2007). A blot of biotin-AHA-labeled samples developed with streptavidin showed similar total levels of newly synthesized proteins in cells expressing KIS and control shRNAs (Fig. 4D). In contrast, immunoblot analysis with specific antibodies showed a substantial decrease $(\sim 50 \%)$ in the newly synthesized levels of AMPARs and PSD-95 in KIS knockdown neurons (Fig. 4E). Levels of VDAC, a mitochondrial protein not regulated by synaptic activity, did not show significant changes. Surface biotinylation assays revealed that KIS knockdown was accompanied by a decrease in the population of the two AMPAR subunits at the cell surface (Fig. $4 F$ ). Together, these data indicate that KIS plays a role in 
A
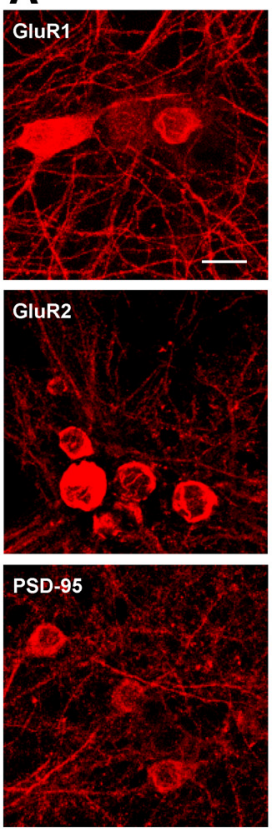
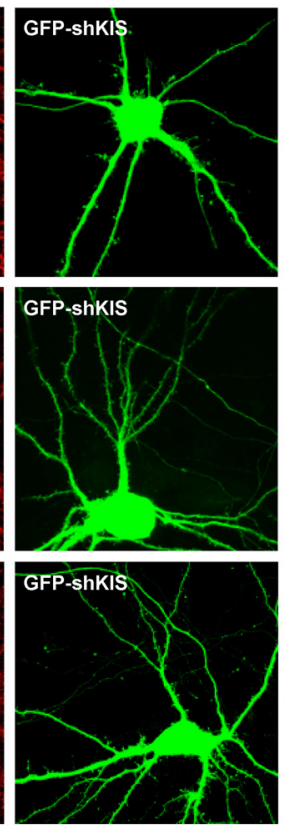
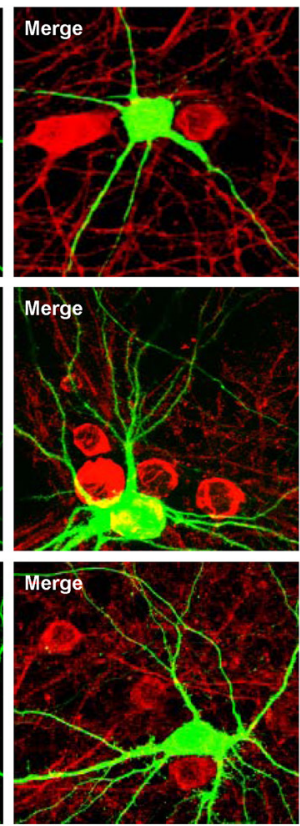

B

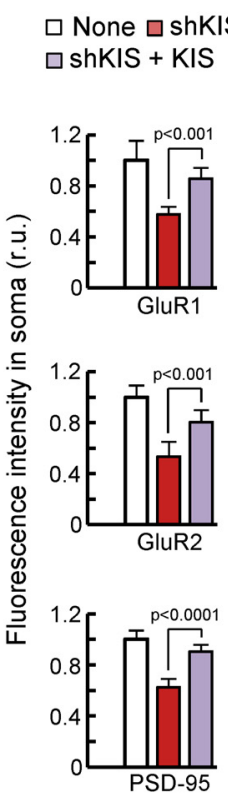

C
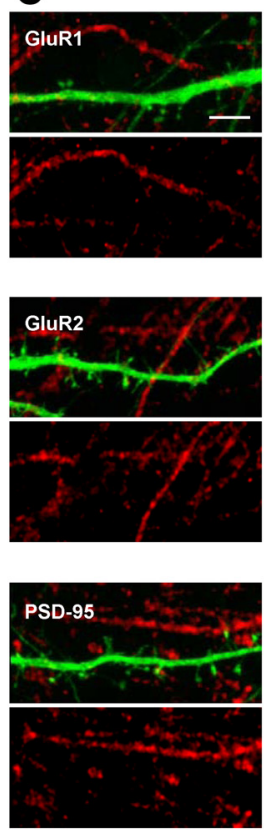

D
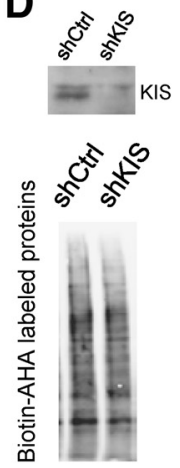

E

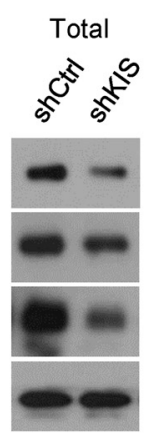

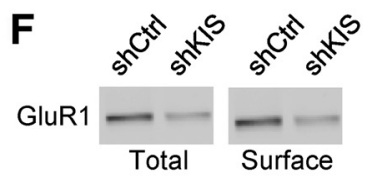

$\square$ shCtrl $\square \square$ shKIS

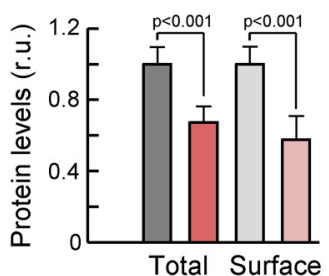

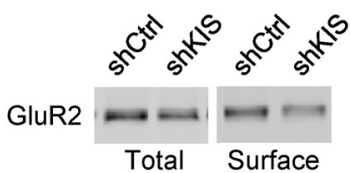

$\square \square$ shCtrl $\square \square$ shKIS

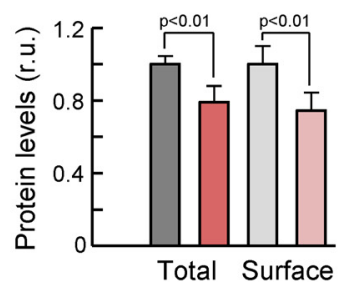

Figure 4. KIS downregulation decreases GluR1, GluR2, and PSD-95 protein levels reducing translation rates. Hippocampal neurons were transfected at 7 DIV with a vector expressing GFP and KIS (shKIS) shRNA, with or without a human KIS-expressing plasmid, and analyzed at 18 DIV by immunofluorescence $(\boldsymbol{A}-\boldsymbol{C})$ or infected at $3-4$ DIV with lentiviral vectors expressing control (shCtrl) or KIS (shKIS) shRNAs, and cultured until 13-14 DIV (D-F).A, Representative images used to quantify GluR1, GluR2, and PSD-95 proteins (red) in transfected cells (GFP-shKIS, green) and untransfected cells as reference. Scale bar, $20 \mu \mathrm{m}$. B, Fluorescence levels in soma of untransfected ( $n=5$ per field), shKIS-transfected $(n=10)$, and shKIS + human KIS cotransfected cells were quantified and mean values and confidence limits $(\alpha=0.05)$ for the mean are plotted. Obtained $p$ values for relevant pairwise $t$ tests are shown. $C$, GluR1, GluR2, and PSD-95 immunofluorescence images (red) of representative neurites of cells (GFP-shKIS, green) from experiment showed in $A$. Scale bar, $5 \mu \mathrm{m}$. D, E, BONCAT analysis. Hippocampal neurons were incubated with the methionine analog AHA (azidohomoalanine) for $4 \mathrm{~h}$, and after coupling to biotin-alkyne, cell extracts were affinity purified with avidin beads. $\boldsymbol{D}$, Total extracts were analyzed by immunoblotting to assess the levels of KIS (top) and biotin-AHA-labeled proteins (bottom). E, GluR1, GluR2, PSD-95, and VDAC (as control) were detected by immunoblotting in cell extracts (total) and avidin-bound fractions (nascent). $\boldsymbol{F}$, Hippocampal neurons were labeled at the surface with biotin and cell extracts (total) and avidin-bound fractions (surface) were analyzed by immunoblotting to quantify protein levels of GluR1 and GluR2. Mean $(n=8)$ and confidence limits $(\alpha=0.05)$ for the mean are plotted. Obtained $p$ values for relevant pairwise $t$ tests are shown.

the de novo protein accumulation of AMPARs and increases their levels at the cytoplasmic membrane.

\section{Regulation of AMPAR levels by KIS requires the presence of CPEB3}

We next sought to identify the molecular mechanism by which KIS regulates AMPAR protein synthesis. As the family of CPEB RNA-binding proteins has been involved in the control of neuronal mRNA translation, we decided to test their ability to interact with KIS. Figure $5 A$ shows CPEB1, CPEB2, and CPEB3 interacting with KIS when expressed in HEK293T cells with similar efficiencies, while CPEB4 was undetectable in our FLAG-KIS immunoprecipitates. In particular, $\mathrm{CPEB} 3$ has been shown to repress translation of both AMPAR subunits, GluR1 and GluR2 (Huang et al., 2006; Pavlopoulos et al., 2011; Chao et al., 2013). Thus, we decided to test whether CPEB3 is involved in KISmediated effects on the synthesis of these proteins. We infected hippocampal neurons with lentiviruses expressing shRNAs against KIS and CPEB3, and analyzed GluR1 and GluR2 protein levels at 13-14 DIV. As already shown in Figure 4, KIS knockdown produced a strong reduction of AMPAR expression (Fig. $5 B, C)$. In contrast, when expression of CPEB3 was downregulated we did not observe significant changes in AMPAR protein levels relative to control cultures. These results partly disagree with those observed by Chao et al. (2013) in hippocampal cultures from CPEB3 knock-out mice, where they showed that ex- 


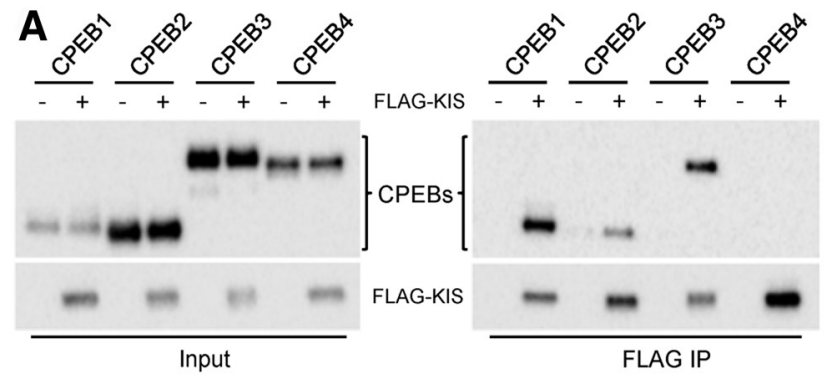

B

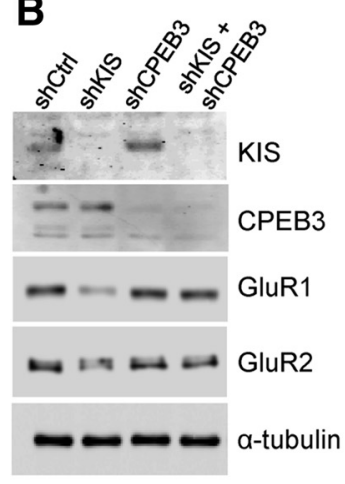

D

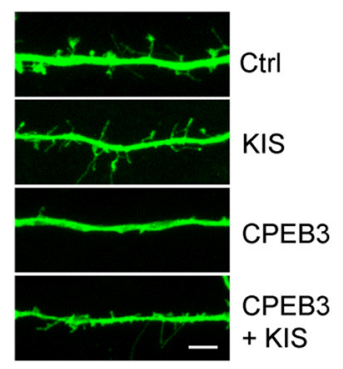

C

$\square$ shCtrl $\square$ shCPEB3

$\square$ shKIS $\square$ shKIS + shCPEB3

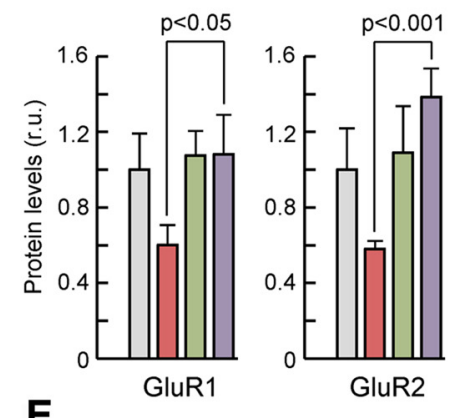

E

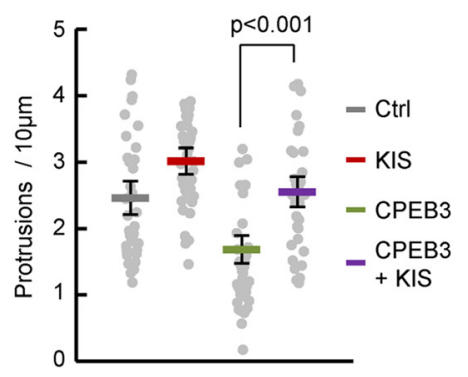

Figure 5. KIS modulates GluR1 and GluR2 translation through CPEB3. A, In vivo interactions between KIS and CPEB proteins. HEK293T cells were cotransfected with vectors expressing CPEB proteins in combination with vectors expressing FLAG or FLAG-KIS. Immunoprecipitation was performed with $\alpha$ FLAG beads, CPEBs, and FLAG-KIS levels in input and immunoprecipitation (IP) samples were analyzed by Western blot. $\boldsymbol{B}$, Hippocampal neurons were infected at 3-4DIV with lentiviral vectors expressing control (shCtrl), KIS (shKIS), or CPEB3 (shCPEB3) shRNAs, and cultured until 13-14 DIV. An immunoblot of whole-cell extracts to quantify KIS, CPEB3, GluR1, GluR2, and $\alpha$-tubulin is shown. C, Protein levels were made relative to $\alpha$-tubulin, and mean values $(n=6)$ and confidence limits $(\alpha=0.05)$ for the mean are plotted. Obtained $p$ values for relevant pairwise $t$ tests are shown. $\boldsymbol{D}$, Hippocampal neurons were transfected at $10 \mathrm{DIV}$ with plasmid vectors expressing GFP and KIS, CPEB3, or KIS + CPEB3 and imaged $24 \mathrm{~h}$ later. Representative neurites are shown. $E$, Quantification of the number of protrusions per $10 \mu \mathrm{m}$ (10 20 $\mu \mathrm{m}$ tracks per neuron) in cells transfected with empty vector $(n=21)$ as control, or plasmids expressing KIS $(n=27)$, CPEB3 $(n=15)$, or KIS + CPEB3 $(n=31)$. Mean values (thick horizontal lines) and confidence limits ( $\alpha=0.05$, thin vertical lines) for the mean are also shown. Obtained $p$ values for relevant pairwise $t$ tests are shown.

pression levels of GluR1 and PSD-95 began to increase in CPEB3 knock-out neurons at 15-19 DIV compared with wild-type neurons. Thus, these discrepancies may likely be due to the fact that neurons were harvested at different DIV or to residual expression of CPEB3 escaping shRNA interference. Notably, loss of KIS did not produce the expected decrease in GluR1 and GluR2 if CPEB3 was also downregulated by coinfection of lentiviruses expressing the corresponding shRNAs (Fig. $5 B, C$ ). These results indicate that KIS is important for high-translation rates of these proteins only in the presence of CPEB3, and suggest that KIS acts to alleviate GluR1 and GluR2 mRNAs from CPEB3-mediated translational inhibition.

\section{KIS stimulates spine development and modulates CPEB3 activity}

It has been shown that overexpression of $\mathrm{CPEB} 3$ reduces the levels of AMPARs and consequently the number of synaptic spines (Huang et al., 2006). Since our data show that KIS and CPEB3 modulate AMPAR expression by a related molecular mechanism, we explored whether dendritic spine phenotype caused by CPEB3 overexpression could be rescued by KIS overexpression. We used the same experimental conditions as Pavlopoulos et al. (2011), i.e., cultures of hippocampal neurons (11 DIV) expressing GFP alone as control or GFP and the indicated proteins. In agreement with the aforementioned published results (Pavlopoulos et al., 2011), the number of spines was reduced when CPEB3 was overexpressed (Fig. 5D,E). In contrast, KIS overexpression resulted in a modest but significant increase in the number of protrusions. More relevant to us, the inhibitory effects produced by CPEB3 overexpression on the number of protrusions per micron were fully reversed when KIS was coexpressed with CPEB3.

It has been shown that CPEB3 binds the 3'UTR of GluR1 and GluR2 mRNAs to repress their translation (Huang et al., 2006; Pavlopoulos et al., 2011). To investigate the possibility that KIS regulates expression of AMPARs by modulating CPEB3 translational activity, we used HEK293T cells transfected with the coding sequence of luciferase fused to the 3'UTR of GluR2 (Pavlopoulos et al., 2011) as a reporter system. As expected $\mathrm{CPEB} 3$ significantly reduced luciferase activity relative to control cells. However, coexpression of KIS reversed significantly the effect of CPEB3 (Fig. 6A). This result strongly supports the notion that KIS modulates GluR2 translation specifically through CPEB3. The interaction between KIS and CPEB3 was resistant to RNase treatment (Fig. 6B) but, when we tested the ability of KIS to modulate the RNA-binding efficiency of CPEB3, we observed that the levels of GluR2 3'UTR in CPEB3 immunoprecipitates were reduced when KIS was coexpressed in HEK293T cells (Fig. 6C).

Overexpression of CPEB3 represses GluR2 translation and decreases polyadenylation of the GluR2 mRNA (Pavlopoulos et al., 2011). To test whether KIS affects the activity of CPEB3 in modulating the length of the poly(A) tail, we performed a polyadenylation assay in HEK293T cells transfected with the same reporter vector used above for luciferase determinations. In agreement with published results (Pavlopoulos et al., 2011), we found that overexpression of CPEB3 was sufficient to shorten the poly(A) tail of the GluR2 3'UTR compared with control cells (Fig. 6D). Interestingly, while protein levels of CPEB3 remained unaffected, the inhibitory effects on polyadenylation were significantly attenuated when KIS was coexpressed (Fig. 6D-G). These results reinforce the notion that KIS could enhance expression of AMPARs by counteracting the inhibitory role of CPEB3.

\section{Discussion}

Dendritic spines are the major sites of information processing in the brain; its maturation is critical for correct brain functioning. Multiple studies have revealed that neuropsychiatric disorders are linked with alterations in dendritic spine morphologies and miswiring of neural circuitry (Penzes et al., 2011). The spine volume depends on the area of the postsynaptic density, but more importantly, it reflects the number of AMPARs and therefore strength of the synaptic connection (Bourne and Harris, 2007). The strong correlation between spine size and synapse strength makes spine remodeling an attractive structural mechanism underlying learning and memory. It is generally assumed that 

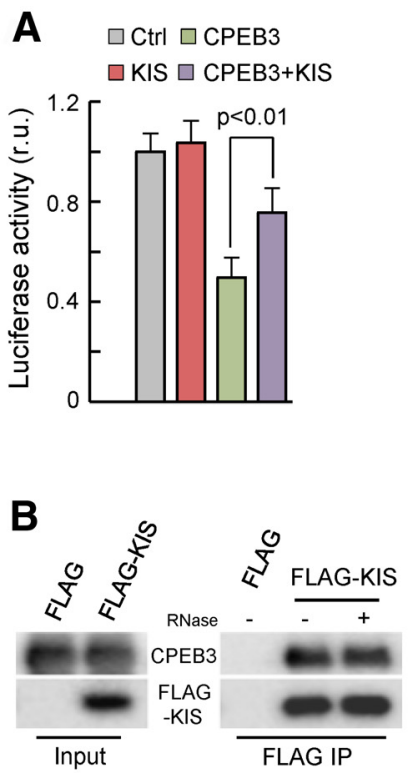
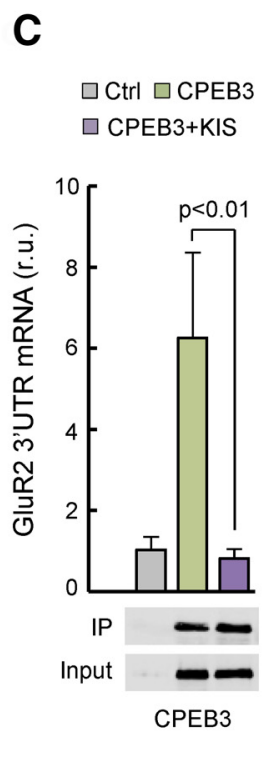

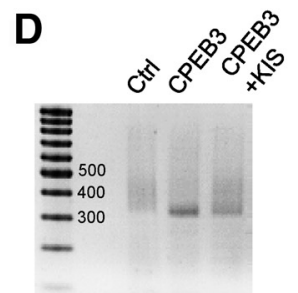

GluR2 3'UTR poly(A)

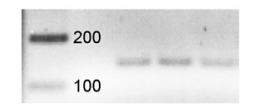

GluR2 3'UTR mRNA

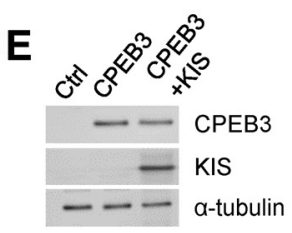

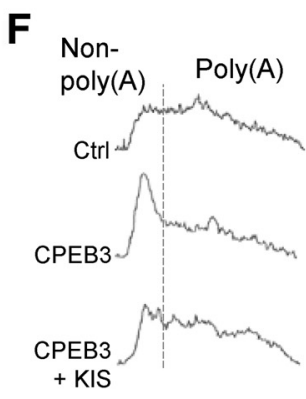

G

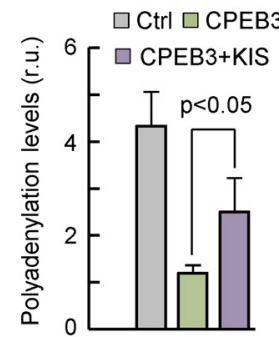

Figure 6. KIS promotes CPEB3 dissociation from GluR2 3'UTR and regulates its polyadenylation. A, Luciferase reporter analysis of the GluR2 $3^{\prime}$ UTR. HEK293T cells were transfected with the Gaussia luciferase ORF fused to the $3^{\prime}$ UTR of GluR2, in combination with plasmid vectors expressing KIS, CPEB3, or CPEB3 + KIS. Values were made relative to those obtained from an empty vector $(\mathrm{Ctrl})$. Mean values $(n=6)$ and confidence limits $(\alpha=0.05)$ for the mean are represented. Obtained $p$ values for relevant pairwise $t$ tests are shown. $\boldsymbol{B}$, Effect of RNase treatment on the association of KIS to (PEB3. Total extracts (input) from HEK293T cells expressing (PEB3 and FLAG or FLAG-KIS were incubated with (+) or without (-) RNase prior to immunoprecipitation (IP), and the corresponding $\alpha$ FLAG immunoprecipitates (FLAG IP), were analyzed by immunoblotting to detect CPEB3 and FLAG-KIS proteins. C, RNA immunoprecipitation and quantitative PCR. HEK293T cells were transfected with the firefly luciferase ORF fused to the 3'UTR of GluR2, in combination with vectors expressing FLAG, FLAG-CPEB3, or FLAG-CPEB3 + KIS. Cell lysates were immunoprecipitated with FLAG IgG, and precipitated mRNAs were reverse transcribed and quantified by RT-qPCR. Luc-GluR2 $3^{\prime} \mathrm{UTR}$ mRNA levels were made relative to GADPH mRNA. Mean values from three independent experiments and confidence limits $(\alpha=0.05)$ for the mean are plotted. Obtained $p$ values for relevant pairwise $t$ tests are shown. $\mathbf{D}$, Polyadenylation assays of the GluR2 $33^{\prime} U$ UTR. Cell extracts from HEK293T cells as in C were used to amplify poly(A) (top) and total (bottom) Luc-GluR2 $3^{\prime}$ UTR mRNAs, and the resulting products were separated by agarose electrophoresis. $E$, Cell extracts as in $\boldsymbol{D}$ were analyzed by immunoblotting to detect CPEB3 and KIS proteins. $\boldsymbol{F}$, Polyadenylation profiles obtained by densitometric analysis of samples as in $\boldsymbol{D}$. $\boldsymbol{G}$, Quantification of relative polyadenylation levels from profiles in $\boldsymbol{F}$ as poly $(\mathrm{A}) /$ nonpoly $(\mathrm{A})$ ratios. Mean values $(n=3)$ and confidence limits $(\alpha=0.05)$ for the mean are represented. Obtained $p$ values for relevant pairwise $t$ tests are shown.

changes in spine morphology are based on rearrangements of the actin cytoskeleton (Hotulainen and Hoogenraad, 2010). However, recent evidence indicates that microtubules enter dendritic spines and control actin polymerization within spines, thus playing an important role in maintenance of spine morphology and synapse maturation (Jaworski et al., 2009; Hu et al., 2011). We propose that KIS could play an important role in coordinating cytoskeleton dynamics and postsynaptic protein synthesis in the context of synaptic plasticity (De Rubeis et al., 2013). KIS modulates the tubulin cytoskeleton in a stathmin-dependent manner (Maucuer et al., 1997; Watabe-Uchida et al., 2006), and we have previously shown that KIS is able to stimulate $\beta$-actin mRNA translation in neurites (Cambray et al., 2009). Here we show that KIS is necessary for appropriate expression of postsynaptic proteins and proper development of synaptic spines. In particular, KIS loss results in a decrease of AMPARs and, as a consequence, a lower presence of these postsynaptic receptors at the cell surface. In agreement with the role of AMPARs in setting the amplitude of synaptic transmission (Kasai et al., 2010), KIS knockdown altered postsynaptic activity and produced an $\sim 30 \%$ decrease in the amplitude of mini-EPSCs. We also show that KIS enhances synthesis of PSD-95, a scaffold postsynaptic protein in excitatory synapses (Sheng and Hoogenraad, 2007) that affects the amplitude of mini-EPSCs (El-Husseini et al., 2000; Zheng et al., 2012), thus contributing to explaining the effects of KIS on synaptic activity.

The relevance of the cytoplasmic polyadenylation complex in synaptic function is highlighted by the important changes in synaptic plasticity that occur in response to depletion of polyadenylation complex factors (Richter and Klann, 2009). CPEB3 has been shown to repress translation of the GluR1 and GluR2 subunits of AMPARs (Huang et al., 2006; Pavlopoulos et al., 2011). In addition to GluR1 and GluR2 mRNAs, a CPEB3 knock-out mice study identified that CPEB3 also plays a role in confining translation of PSD-95 and NMDAR subunit mRNAs (Chao et al., 2013). We have found that KIS regulates AMPAR expression in a CPEB3-dependent manner in hippocampal neurons. On the other hand, KIS is able to counteract CPEB3 inhibitory effects on translation and polyadenylation of a GluR2-3'UTR reporter mRNA in a heterologous setting, which could at least partly explain why KIS alleviates GluR1 and GluR2 mRNAs from CPEB3mediated translational inhibition in hippocampal neurons. However, CPEB3 does not require cytoplasmic polyadenylation for translational repression (Huang et al., 2006), which suggests that the observed polyadenylation defects could be a consequence of translational inhibition. Notably, KIS was able to reduce the levels of GluR2 3'UTR in CPEB3 immunoprecipitates when coexpressed in HEK293T cells. Thus, KIS could compete with CPEB3 for binding to target RNAs or, alternatively, KIS could induce a conformational change in CPEB3 that would decrease its affinity for RNA. In agreement with this idea, it has recently been reported that KIS enhances the transcriptional repressor activity of CATS through protein-protein interactions (Archangelo et al., 2013).

KIS has been found to interact with elongation factor eEF1A, suggesting that it could also act by reactivating translation of elongation-arrested mRNAs. In this regard, CPEB2 and CPEB3 have been shown to interact with $\mathrm{eEF} 2$, downregulating its GTPase activity and, hence, hindering translation elongation of 
hypoxia-inducible factor- $1 \alpha$ (Chen and Huang, 2012). Interestingly, it has been recently shown that MAP1b mRNA is repressed at the elongation step of translation in the RNA granule, waiting to be reactivated for translation (Graber et al., 2013). Contrary to the current assumption that RNAs are repressed at the initiation step, these observations suggest that elongation is a critical step for regulation of translation in synaptic plasticity. Thus, CPEB3 could regulate translation at two levels, initiation and elongation, through specific interactors and with different effects on polyadenylation of the target mRNA. While regulation of initiation could be linked to a more persistent inhibition during transport, stalling the ribosome at elongation could allow a more dynamic regulation at the synapse.

Elevated protein levels of eEF1A in FMRP-lacking neurons sequester the E3 ubiquitin-protein ligase Mdm2 preventing PSD-95 ubiquitination and synapse elimination (Tsai et al., 2012). We have observed that KIS is important for attaining proper levels of PSD-95 (Fig. 4). In addition to possible effects at the translation level, the interaction of KIS with eEF1A (Cambray et al., 2009) in activated synapses could prevent this elongation factor from sequestering Mdm2, which, as a consequence, would stabilize PSD-95 in the postsynaptic spine.

Accumulating evidence suggests that synthesis of many synaptic proteins is subject to post-transcriptional control at many different levels with concerted actions of multiple RNA-binding proteins and regulatory interacting proteins. Thus, genetic deletion of 4E-BP2 in mice upregulates translation of AMPARs (Ran et al., 2013). Moreover, it has been shown that microRNAs could directly or indirectly influence the protein levels of postsynaptic proteins (Muddashetty et al., 2011; Harraz et al., 2012; Saba et al., 2012). All these findings suggest that multilevel control of the synthesis of these synaptic proteins is critical for proper synaptic plasticity and thus for accurate learning and memory processes (Holt and Schuman, 2013). As another control layer, monoubiquitination of CPEB3 by Neuralized 1 converts CPEB3 from a repressor to an activator to promote polyadenylation-induced translation of GluR1 and GluR2 mRNAs (Pavlopoulos et al., 2011). Our experimental data show that control neurons maintain similar levels of AMPARs compared with CPEB3 knockdown neurons, suggesting that CPEB3 is already repressed in control neurons, probably by the concerted action of Neuralized 1 and KIS. Consistent with this model, the fact that in KIS knockdown neurons we did not observe a complete loss of AMPARs underlines the activating role of Neuralized1 on CPEB3 (Pavlopoulos et al., 2011) and the TOR pathway on 4E-BP proteins (Costa-Mattioli et al., 2009; Hoeffer and Klann, 2010).

Since it is involved as a modulator of microtubules (Maucuer et al., 1997; Watabe-Uchida et al., 2006; Langenickel et al., 2008), we propose that KIS could harmonize local dynamics of the tubulin cytoskeleton and postsynaptic protein expression, thus playing a key role in the mechanisms that ensure proper spatial and timely activation of synapses. Future studies should elucidate the synaptic inputs that activate KIS, which will allow us to better understand the molecular mechanisms of synaptic plasticity.

\section{References}

Archangelo LF, Greif PA, Maucuer A, Manceau V, Koneru N, Bigarella CL, Niemann F, dos Santos MT, Kobarg J, Bohlander SK, Saad ST (2013) The CATS (FAM64A) protein is a substrate of the Kinase Interacting Stathmin (KIS). Biochim Biophys Acta 1833:1269-1279. CrossRef Medline

Bièche I, Manceau V, Curmi PA, Laurendeau I, Lachkar S, Leroy K, Vidaud D, Sobel A, Maucuer A (2003) Quantitative RT-PCR reveals a ubiquitous but preferentially neural expression of the KIS gene in rat and human. Brain Res Mol Brain Res 114:55-64. Medline

Bosch M, Hayashi Y (2012) Structural plasticity of dendritic spines. Curr Opin Neurobiol 22:383-388. CrossRef Medline

Bourne J, Harris KM (2007) Do thin spines learn to be mushroom spines that remember? Curr Opin Neurobiol 17:381-386. CrossRef Medline

Cambray S, Pedraza N, Rafel M, Garí E, Aldea M, Gallego C (2009) Protein kinase KIS localizes to RNA granules and enhances local translation. Mol Cell Biol 29:726-735. CrossRef Medline

Caroni P, Donato F, Muller D (2012) Structural plasticity upon learning: regulation and functions. Nat Rev Neurosci 13:478-490. CrossRef Medline

Chao HW, Tsai LY, Lu YL, Lin PY, Huang WH, Chou HJ, Lu WH, Lin HC, Lee PT, Huang YS (2013) Deletion of CPEB3 enhances hippocampusdependent memory via increasing expressions of PSD95 and NMDA receptors. J Neurosci 33:17008-17022. CrossRef Medline

Chen PJ, Huang YS (2012) CPEB2-eEF2 interaction impedes HIF- $1 \alpha$ RNA translation. ЕMBO J 31:959-971. CrossRef Medline

Costa-Mattioli M, Sossin WS, Klann E, Sonenberg N (2009) Translational control of long-lasting synaptic plasticity and memory. Neuron 61:10-26. CrossRef Medline

Darnell JC, Richter JD (2012) Cytoplasmic RNA-binding proteins and the control of complex brain function. Cold Spring Harb Perspect Biol 4:a012344. CrossRef Medline

De Rubeis S, Pasciuto E, Li KW, Fernández E, Di Marino D, Buzzi A, Ostroff LE, Klann E, Zwartkruis FJ, Komiyama NH, Grant SG, Poujol C, Choquet D, Achsel T, Posthuma D, Smit AB, Bagni C (2013) CYFIP1 coordinates mRNA translation and cytoskeleton remodeling to ensure proper dendritic spine formation. Neuron 79:1169-1182. CrossRef Medline

Dieterich DC, Lee JJ, Link AJ, Graumann J, Tirrell DA, Schuman EM (2007) Labeling, detection and identification of newly synthesized proteomes with bioorthogonal noncanonical amino-acid tagging. Nat Protoc 2:532540. CrossRef Medline

El-Husseini AE, Schnell E, Chetkovich DM, Nicoll RA, Bredt DS (2000) PSD-95 involvement in maturation of excitatory synapses. Science 290: 1364-1368. Medline

Graber TE, Hébert-Seropian S, Khoutorsky A, David A, Yewdell JW, Lacaille JC, Sossin WS (2013) Reactivation of stalled polyribosomes in synaptic plasticity. Proc Natl Acad Sci U S A 110:16205-16210. CrossRef Medline

Han EB, Stevens CF (2009) Development regulates a switch between postand presynaptic strengthening in response to activity deprivation. Proc Natl Acad Sci U S A 106:10817-10822. CrossRef Medline

Harraz MM, Eacker SM, Wang X, Dawson TM, Dawson VL (2012) MicroRNA-223 is neuroprotective by targeting glutamate receptors. Proc Natl Acad Sci U S A 109:18962-18967. CrossRef Medline

Hoeffer CA, Klann E (2010) mTOR signaling: at the crossroads of plasticity, memory and disease. Trends Neurosci 33:67-75. CrossRef Medline

Holt CE, Schuman EM (2013) The central dogma decentralized: new perspectives on RNA function and local translation in neurons. Neuron 80: 648-657. CrossRef Medline

Hotulainen P, Hoogenraad CC (2010) Actin in dendritic spines: connecting dynamics to function. J Cell Biol 189:619-629. CrossRef Medline

Huang YS, Kan MC, Lin CL, Richter JD (2006) CPEB3 and CPEB4 in neurons: analysis of RNA-binding specificity and translational control of AMPA receptor GluR2 mRNA. EMBO J 25:4865-4876. CrossRef Medline

Hu X, Ballo L, Pietila L, Viesselmann C, Ballweg J, Lumbard D, Stevenson M, Merriam E, Dent EW (2011) BDNF-induced increase of PSD-95 in dendritic spines requires dynamic microtubule invasions. J Neurosci 31: 15603. CrossRef Medline

Jaworski J, Kapitein LC, Gouveia SM, Dortland BR, Wulf PS, Grigoriev I, Camera P, Spangler SA, Di Stefano P, Demmers J, Krugers H, Defilippi P, Akhmanova A, Hoogenraad CC (2009) Dynamic microtubules regulate dendritic spine morphology and synaptic plasticity. Neuron 61:85-100. CrossRef Medline

Jiang M, Chen G (2006) High Ca2+-phosphate transfection efficiency in low-density neuronal cultures. Nat Protoc 1:695-700. CrossRef Medline

Kasai H, Hayama T, Ishikawa M, Watanabe S, Yagishita S, Noguchi J (2010) Learning rules and persistence of dendritic spines. Eur J Neurosci 32:241249. CrossRef Medline

Kato K, Sekino Y, Takahashi H, Yasuda H, Shirao T (2007) Increase in AMPA receptor-mediated miniature EPSC amplitude after chronic 
NMDA receptor blockade in cultured hippocampal neurons. Neurosci Lett 418:4-8. CrossRef Medline

Kielkopf CL, Lücke S, Green MR (2004) U2AF homology motifs: protein recognition in the RRM world. Genes Dev 18:1513-1526. CrossRef Medline

Langenickel TH, Olive M, Boehm M, San H, Crook MF, Nabel EG (2008) KIS protects against adverse vascular remodeling by opposing stathminmediated VSMC migration in mice. J Clin Invest 118:3848-3859. CrossRef Medline

Liu-Yesucevitz L, Bassell GJ, Gitler AD, Hart AC, Klann E, Richter JD, Warren ST, Wolozin B (2011) Local RNA translation at the synapse and in disease. J Neurosci 31:16086-16093. CrossRef Medline

Manceau V, Kremmer E, Nabel EG, Maucuer A (2012) The protein kinase KIS impacts gene expression during development and fear conditioning in adult mice. PLoS One 7:e43946. CrossRef Medline

Maucuer A, Ozon S, Manceau V, Gavet O, Lawler S, Curmi P, Sobel A (1997) KIS is a protein kinase with an RNA recognition motif. J Biol Chem 272:23151-23156. CrossRef Medline

Muddashetty RS, Nalavadi VC, Gross C, Yao X, Xing L, Laur O, Warren ST, Bassell GJ (2011) Reversible inhibition of PSD-95 mRNA translation by miR-125a, FMRP phosphorylation, and mGluR signaling. Mol Cell 42: 673-688. CrossRef Medline

Pavlopoulos E, Trifilieff P, Chevaleyre V, Fioriti L, Zairis S, Pagano A, Malleret G, Kandel ER (2011) Neuralized1 activates CPEB3: a function for nonproteolytic ubiquitin in synaptic plasticity and memory storage. Cell 147:1369-1383. CrossRef Medline

Penzes P, Rafalovich I (2012) Regulation of the actin cytoskeleton in dendritic spines. Adv Exp Med Biol 970:81-95. CrossRef Medline

Penzes P, Cahill ME, Jones KA, VanLeeuwen JE, Woolfrey KM (2011) Dendritic spine pathology in neuropsychiatric disorders. Nat Neurosci 14: 285-293. CrossRef Medline

Ramachandran B, Frey JU (2009) Interfering with the actin network and its effect on long-term potentiation and synaptic tagging in hippocampal CA1 neurons in slices in vitro. J Neurosci 29:12167-12173. CrossRef Medline

Ran I, Gkogkas CG, Vasuta C, Tartas M, Khoutorsky A, Laplante I, Parsyan A, Nevarko T, Sonenberg N, Lacaille JC (2013) Selective regulation of
GluA subunit synthesis and AMPA receptor-mediated synaptic function and plasticity by the translation repressor 4E-BP2 in hippocampal pyramidal cells. J Neurosci 33:1872-1886. CrossRef Medline

Richter JD, Klann E (2009) Making synaptic plasticity and memory last: mechanisms of translational regulation. Genes Dev 23:1-11. CrossRef Medline

Saba R, Störchel PH, Aksoy-Aksel A, Kepura F, Lippi G, Plant TD, Schratt GM (2012) Dopamine-regulated microRNA MiR-181a controls GluA2 surface expression in hippocampal neurons. Mol Cell Biol 32:619-632. CrossRef Medline

Sheng M, Hoogenraad CC (2007) The postsynaptic architecture of excitatory synapses: a more quantitative view. Annu Rev Biochem 76:823-847. CrossRef Medline

Shumyatsky GP, Malleret G, Shin RM, Takizawa S, Tully K, Tsvetkov E, Zakharenko SS, Joseph J, Vronskaya S, Yin D, Schubart UK, Kandel ER, Bolshakov VY (2005) Stathmin, a gene enriched in the amygdala, controls both learned and innate fear. Cell 123:697-709. CrossRef Medline

Smith WB, Starck SR, Roberts RW, Schuman EM (2005) Dopaminergic stimulation of local protein synthesis enhances surface expression of GluR1 and synaptic transmission in hippocampal neurons. Neuron 45: 765-779. CrossRef Medline

Tolino M, Köhrmann M, Kiebler MA (2012) RNA-binding proteins involved in RNA localization and their implications in neuronal diseases. Eur J Neurosci 35:1818-1836. CrossRef Medline

Tsai NP, Wilkerson JR, Guo W, Maksimova MA, DeMartino GN, Cowan CW, Huber KM (2012) Multiple autism-linked genes mediate synapse elimination via proteasomal degradation of a synaptic scaffold PSD-95. Cell 151:1581-1594. CrossRef Medline

Watabe-Uchida M, John KA, Janas JA, Newey SE, Van Aelst L (2006) The Rac activator DOCK7 regulates neuronal polarity through local phosphorylation of stathmin/Op18. Neuron 51:727-739. CrossRef Medline

Zhang J, Yang Y, Li H, Cao J, Xu L (2005) Amplitude/frequency of spontaneous $\mathrm{mEPSC}$ correlates to the degree of long-term depression in the CA1 region of the hippocampal slice. Brain Res 1050:110-117. Medline

Zheng S, Gray EE, Chawla G, Porse BT, O’Dell TJ, Black DL (2012) PSD-95 is post-transcriptionally repressed during early neural development by PTBP1 and PTBP2. Nat Neurosci 15:381-388, S1. CrossRef Medline 